\title{
JOSÉ MARTÍ ANTE LAS CIRCUNSTANCIAS \\ DE LA GLOBALIZACIÓN NEOLIBERAL CONTRARIAS A LA IDENTIDAD NACIONAL
}

\section{José Luis de la Tejera Galí}

\section{RESUMEN}

Se pretende hacer un corte epistemológico sobre los términos identidad, neoliberalismo y globalización.

El pensamiento antillanista está inmerso, con sus especificidades, en el americanista. El Apóstol de la independencia de Cuba y luchador por la segunda independencia de América Latina y el Caribe, José Martí, contribuyó a la búsqueda de una identidad en sus escritos y praxis revolucionaria. Sus enunciados tienen plena vigencia en nuestro mundo actual y se ven amenazados por la teoría y práctica de la globalización neoliberal.

El redimensionar un pensamiento antillanista vs. el foráneo avasallante desde la óptica martiana y la experiencia cubana puede conducir a un verdadero encuentro entre países hermanos de esa zona geográfica.

En el trabajo se analizan algunos núcleos temáticos martianos, principalmente de su texto fundacional "Nuestra América" y el alcance de éstos en los momentos actuales en que las prácticas neoliberales atenazan el verdadero desarrollo de nuestros países. Además, se parte del recorrido del meta discurso sobre la identidad en América Latina y la posición que ocupa el que se inspira en los postulados martianos.

* Profesor Titular del Instituto Superior Pedagógico Frank País Garcia y Presidente Socicdad Cultural José Martí en Santiago de Cuba. 
"América mestiza", "identidad", "transculturación", globalización, neoliberalismo, unidad.

Apocalíptico y (des)integrador sin una marca cultural identitaria se presenta el casi presente y futuro de la humanidad como una posibilidad de ir creciendo. Del otro lado de la moneda un nuevo orden mundial presidido por el equilibrio ético - social y económico - cultural aspirado.

Tales son, desde nuestro punto de vista, las expectativas generales posibles a partir del desarrollo de las fuerzas y circunstancias que rigen el devenir de la historia de la sociedad en que vivimos. Estamos puntuando polos opuestos, quizás de manera excluyente de otras alternativas u otros paliativos. Realmente, ir al análisis de un fenómeno social desde un único presupuesto teórico es un riesgo, pues su hipótesis debe tener indicadores ya explorados y verificada en cierta medida. De otro modo su resultante puede ser negativa. Por eso insistimos que tomamos partido por la posibilidad de que emerjan variantes satisfactorias para los pueblos.

El desarrollo del hombre es así. Hay veces que con el decursar del tiempo encontramos sorpresas que muchos no previmos. Así sucedió con el muro de Berlín, con la extinción de la URSS, con los terribles sucesos del 11 de septiembre en EE.UU.

En nuestra América mestiza, surgida de los avatares del (des)encuentro entre la cultura, idiosincrasia y maneras de pensar y hacer entre el mundo europeo y el americano, Calibán y Próspero' dieron como resultado un tipo de opresión y vasallaje, pero también la conformación de un hombre con peculiaridades que lo marcarían con un carácter distintivo. Se iría formando una figura con una identidad otra, que parte de 
su pasado andrógeno y va evolucionando a razón de factores también exógenos y los demandados de la propia contradicción con la metrópoli y las necesidades y aspiraciones del nuevo sujeto.

El sabio Fernando Ortíz opone al vocablo aculturación el de transculturación para explicar "las complejísimas transmutaciones de cultura (...) sin conocer las cuales es imposible entender la evolución del pueblo cubano, así en lo económico como en lo institucional, jurídico, ético, religioso, artístico, linguístico, psicológico, sexual y en los demás aspectos de la vida". ${ }^{2}$ Este proceso de integración no fue sólo en Cuba. Sin homologarlo en todos sus ingredientes, en otras latitudes del continente latinoamericano y el Caribe ocurrió en diferente medida. Así la identidad nuestra ${ }^{3}$ tiene mucho que ver con el proceso explicado con anterioridad.

La identidad, pues, no es estática, surge como el ave Fénix, aunque no con carácter repetitivo, mimético, tiende a cambios cualitativos y quizás cuantitativos. Es un proceso. Según el acercamiento que realicemos hay múltiples definiciones. Hacia el interior de una sociedad o un individuo, podemos considerarla como "el reconocimiento de la multilateralidad de nuestro ser cultural, pues también es el principio de la alteralidad. Tú en relación con los demás", ${ }^{4}$ según Carlos Andújar, quien además reafirma el papel de las ideologías en el proceso identitario.

El término identidad es, casi siempre, asumido desde la perspectiva sociocultural. Nos parece interesante el que "alude al conjunto de elementos objetivos y subjetivos específicos de alguna entidad dada que le aportan un sello distintivo y diferenciador de otros". 5

La investigadora cubana Maritza García Alonso, partiendo de los estudios y sistematizaciones del paraguayo Ticio Esco- 
bar, describe la evolución de las conceptualizaciones del término identidad en su devenir histórico en esta cita in extenso que transcribimos:

Se puede descubrir que en esa evolución del concepto, la identidad no es mera ontología, es decir, conjunto de rasgos distintivos de una entidad cultural dada - constituyéndose en la denominada <mismidad $>-$, sino que incluye la referencia a otra entidad distinta, con la cual se interactúa y que es concebida así como un <otro>.

Al seguir su evolución, observamos la denotación identidad para aludir a fenómenos en diversos ámbitos de la realidad sociocultural, tanto en análisis generales del tipo filosófico, etnológico, literario, musicológico, como en estudios de grupos enmarcables: familia, comunidad local, territorio, provincia, nación, región supranacional, entre otros; o en cortes transversales en el tiempo para cualesquiera de estos grupos. Esto ha llevado a concebir la existencia fenoménica de la identidad plural, esto es, las identidades.

Sin el rastreo de esta trayectoria ya era posible intuir que el concepto identidad refiere aigo más que conjuntos cerrados de cualidades sobre alguna entidad cultural, o algo más que diseños estructurados de representaciones simbólicas sobre la misma. El concepto de identidad refiere procesos dinámicos

Este dinamismo al interior de la identidad hace, a nivel de la conceptualización, que signifique un proceso de alta complejidad, donde cada componente se articula con otros y forma un entramado que marca al sujeto o entidad identitaria: una persona, una comunidad, un país; un grupo religioso, político, una etnia; en fin: una cultura en su devenir, relaciones $\mathrm{y}$ alcances.

Con la identidad, nos parece, se puede expresar, en térmi550 
nos de símil, la consideración de Lenin sobre la cultura del dominador y la del dominado en una determinada sociedad. Una impone sus reglas de subordinación y comprensión del mundo y sus prácticas, y la otra las acepta o rechaza, parcial o totalmente. La "mismidad" o la "otredad" del sujeto en un espacio sociocultural tiene relación con el sentido de pertenencia y status en esos polos culturales. La identidad se relaciona con la imagen o representación elaborada, con la cosmovisión del grupo social privilegiado que la detenta, perfecciona, extiende $y$, por otro lado, el receptor de ella, quien será, también, su portador (consciente o no). Todo en un proceso antiestático y lleno de significaciones de diversa índole que en última instancia determine, conforme, la autoconciencia del individuo y las proyecciones organizativas sociales.

Según el modo de considerar el hecho identitario como discurso, coincidimos en que existen, a saber, cuatro: humanístico, ideopolítico, teórico - práctico, y teórico - instrumental, según una tipología obtenida del análisis de las fuentes.

De esta estratificación tipológica con respecto a las características investigadas sobre la identidad latinoamericana y los modos de pensarla, "el ideopolítico" se parece al "humanístico" en tanto parten de la esencia fundacional de la cultura latinoamericana, pero se detiene en la presencia del otro. El sujeto existente en nuestras tierras, el hombre americano, desde el Río Bravo hasta la Patagonia y las tierras caribeñas, en particular las marcadas por la cruz y la espada españolas, está presentado en el raigal ensayo martiano "Nuestra América", fuente nutricia del modo ideopolítico de ver la identidad.

El discurso o aspiración del "ser" y el del "querer ser" son antagónicos por su esencia, aunque a veces en apariencia no lo sean. Hay una distancia entre lo real y lo aspirado que puede conllevar a su contrapolo. No es lo mismo el hombre americano con taparrabo, "levita" o jeans, si esta indumentaria exter- 
na no parte de una realidad epocal contextual y del desarrollo material y cultural de él y de su entorno social. No es igual que el hombre de nuestras tierras que presenta características y peculiaridades específicas y está considerando nuevas que no tienen que ver con su propio desarrollo en diversos órdenes. "Ni parisinos", como pensaba Martí, ni neoyorquinos como modelos aspirados del "querer ser". Este discurso de la identidad como máscara es extremadamente pernicioso y fue advertido en algunas de sus aristas por el pensador cubano en varios de sus textos. De lo que se trata es de un modo del discurso que logre a través de la concientización, la internalización de la verdadera identidad de "aquí", opuesta a la de "allá" y sus modos conductuales y operacionales. Los deícticos opuestos marcan, al final, una cosmovisión en oposición. El modo de pensar sobre la máscara extrapolarizante de nuestro "ser", desdibuja la figura "hombre americano" y su pensar americano.

En Cuba, Roberto Fernández Retamar ha inquirido al pensamiento martiano para encontrar las coordenadas identitarias y su referente avasallador: el "otro". En Para una teoría de la Literatura hispanoamericana, publicada en 1975 por Retamar, ya está presente un corpus orgánico desde la literatura que observa las esencias de lo americano y las influencias foráneas hasta en la recopilación de 1979 Calibán y otros ensayos (véase referencia No. 1), donde el autor vuelve a la carga sobre nuestro devenir como hombre americano y caribeño y la presencia de los polos opuestos representados por dos figuras literarias provenientes del ingenio de Shakespeare. Lo que está en juego es el análisis intelectual que desmitifique un pensamiento anti - identitario, impuesto y aceptado con rapidez inusual por cierta "inteligencia", aunque siempre ha habido voces discordantes. Retamar, para sintetizar nosotros, busca el origen en el colonialismo y el neocolonialismo. Hoy por hoy, el "otro" continúa, aunque haya ocurrido un cambio de jefaturas. La penetración y dominio del "otro" se manifiesta en múl- 
tiples alcances. Algunas anuencias ante el neoliberalismo son un buen ejemplo de la influencia del "otro" y su continutum

Una de las constantes ha sido la relación centro - periferia, nosotros y el otro:

De ahí que la denuncia de las condiciones históricas de coloniaje y neocoloniaje vigentes, el análisis de las consecuencias culturales que esta situación macroestructural ha traido para las sociedades latinoamericanas, y la necesidad de un nuevo orden político que elimine la relación vertical de dependencia, constituyen el centro de las argumentaciones alrededor de las cuales se construye el discurso. ${ }^{8}$

Nosotros, como observaremos en el ideario martiano, tenemos todo un patrimonio cultural resultado de una evolución dialéctica en todos los órdenes. Hay un "constructo" de americanidad, de antillaneidad, de lo propio opuesto a los rasgos o tendencias manipuladoras anti - identitarias. Hay un discurso que analiza este fenómeno desde la óptica política y devela un ser, un pensar y hacer desde nuestro contexto e idiosincrasia peculiar. Esta praxis discursiva de honda cala martiana nos sitúa en posición defensiva para propiciar la ofensiva a nivel de las ideas culturales y las prácticas políticas verdaderas y honestas antineoliberales.

El resto de los modos tiende a matizaciones interesantes para el estudio fenoménico: el "teórico - político" busca demostraciones del alcance de los procesos identitarios desde una posición crítica para la búsqueda de alternativas eficaces y la presencia de verdaderos estudios sobre la cultura popular y sus sujetos. El modo "teórico instrumental" se perfila desde un nuevo academicismo que intenta obtener un metapensamiento sobre el decursar de la identidad a nivel conceptual con posibilidades de aplicación para su análisis.

Los cuatro modos de analizar el discurso sobre la identidad 
son posiciones que se basan en cómo se ha visto el referente identidad en nuestro contexto. Para esta ponencia, el momento martiano es muy pertinente porque encierra claves y lecturas productivas para las circunstancias actuales. No obstante, dejamos por sentado que los otros modos pueden considerarse o reconsiderarse, aspecto en el cual no hemos pensado y lo dejamos fuera de nuestro objetivo.

La necesidad de una "construcción social" en la que la identidad nacional sea expedita de una fuerza que aparte la otredad negativa y nos reencontremos cada vez con más fuerzas y estrategias acertadas, hará de la América mestiza un contén ante la aldea global neoliberal. El diseño martiano aún tiene mucho que decir para esta generación de hombres y mujeres de las Antillas y del continente de habla e intereses comunes, incluso, nos parece que para todos los de esta parte del mundo, independientemente del idioma y origen colonial, pues todos sufrimos procesos de dominación y estamos ante la misma encrucijada y las mismas fuerzas foráneas; además, la necesidad de respeto y desarrollo son comunes, pues, "cada hombre, si mira atentamente, construye el mundo" ". De esa humanidad, nosotros somos parte doliente con derecho a un destino mejor desde una comunidad específica o microespacio sociocultural hasta toda nuestra amplitud geográfica o macroespacio físico geocultural americano.

Decíamos más arriba que el discurso sobre la identidad tiene mucho que ver con José Martí. Creemos que también el metadiscurso ha recibido esta influencia. ¡Por qué Martí? ¿Por qué este "hombre - síntesis" del quehacer y el pensamiento nuestro, que tiene por puntas de su estrella a Simón Bolívar, Ramón Emeterio Betances, Eugenio María Hostos y una innumerable pléyade de hombres ilustres de todas las partes del planeta?. Si la identidad contiene las respuestas a las preguntas ¿quiénes somos?, ¿de dónde venimos?, ¿cómo actuamos?, ¿hacia dónde 
nos proyectamos?, ¿qué nos caracteriza como sujeto y/o conjunto social? ; y por supuesto, conforma un universo movible y profundamente complejo, entonces partamos del pensamiento martiano para nuestro comentario, luego de recorrer algunos aspectos de la conformación cosmovisiva del hombre nacido en esta parte del mundo y el discurso sobre la identidad.

Un acercamiento al problema anterior lo podemos realizar a partir de un corte, solamente metodológico y sin olvidar el todo de la obra del Apóstol cubano y obtener ganancias cognoscitivas a partir del estudio de algunos rasgos de "Nuestra América".

Publicado este ensayo el primero de enero de 1891 en la "Revista Ilustrada" de Nueva York y el día 30 del propio mes en el periódico mexicano "El Partido liberal", dirigido principalmente a los sectores de habla castellana dentro de los Estados Unidos y México, es un artículo o ensayo, según la clasificación que adoptemos, fundacional sobre su proyecto programático para toda la América mestiza.

Ora desde el punto de vista linguístico- estilístico con su peculiar estructura a manera de discurso oral, su belleza y funcionalidad estilística y su enriquecido vocabulario, su sentido comunicativo precisado hacia la argumentación de las ideas medulares, incluso con la repetición gradada para lograr, en última instancia su propósito de persuadir y convencer al lector; ora, la construcción de un texto ideológico a partir de análisis de valor histórico del devenir del hombre nacido en nuestras tierras y la presencia de nudos temáticos, con enorme carga contenidista y la utilización de recursos literarios para expresarlos, "Nuestra América" sobrepasa el alcance epocal y se proyecta como un muro ante los anti - identitarios neoliberales globalizadores.

Aunque muy conocida, creemos que la apertura del ensayo debe ser recordada: 
Cree el aldeano vanidoso que el mundo entero es su aldea, y con tal que él quede de alcalde. o le mortifique al rival que le quitó la novia o le crezcan en la alcancía los ahorros, ya da por bueno el orden universal, sin saber de los gigantes que llevan siete leguas en las botas y le pueden poner la bota encima, ni de la pelea de los cometas en el Cielo, que van por el aire dormidos engullendo mundos. Lo que quede de aldea en América ha de despertar: ${ }^{10}$

Martí cuestiona el orden establecido, donde cultural y políticamente el sujeto americano se debate ante dictaduras, militarismo, caudillismo, envidias, intereses económicos, etcétera. y algunos tienen su mirada en los modelos foráneos o ignoran la propia realidad importándole sólo la personal. En tal sentido estas actitudes desdibujan el pensar y hacer americanos para buscar proyectos alejados de su contexto.

A este llamado hacia lo propio equilibrado, Martí explicita otro componente de mayor peligro, el papel hegemónico y expansionista de los yanquis, cuyo estadío como formación económico social estaba en los albores de un capitalismo monopolista con la concentración de capital y la acción de los grandes bancos. La predicción martiana hace más de una centuria y media se ha hecho realidad. En lo económico, el nudo gordiano del Fondo Monetario Internacional cada vez es más opresivo. Economías subordinadas a intereses foráneos que conllevan a desastres en la producción, aunque en el mejor de los casos exista la ilusión de empresas nacionales propias y libres que, paradójicamente, aunque lo fueran, están sujetas a los vaivenes del mercado internacional.

Si el orden universal aspirado, según el texto, era un peligro, el mayor consistía en caer en las manos del gigante norteño. Iguales circunstancias tenemos hoy, a pesar de la experiencia acumulada en todos estos años de independencia en nuestros 
países. La "segunda independencia" que Martí solicitó aún es un acto utópico, en su sentido literal.

Inmediatamente Martí da la clave ante las circunstancias citadas: "trincheras de ideas valen más que trincheras de piedra"." Es la inteligencia de un discurso no dependiente para concientizar a los pueblos. Un pensamiento contestatario y desde nuestra realidad, donde se construya un contén a la invasión ideológica de los "otros". "Ideas" del constructo americano contextual, lo que equivale al ser, al "juicio", al pensar, a la identidad de cada pueblo de esta zona geográfica. Dentro del alcance de "idea", está la unidad de los pueblos mediante el proceso de interrelación cognoscitiva y autorreconocimiento. Necesarios para una identidad propia y una suprarregional de hermandad latinoamericana y antillana: "Los pueblos que no se conocen han de darse prisa para conocerse, como quienes van a pelear juntos", ${ }^{2}$ sin latrocinios ni infamias con el vecino. La solidaridad y respeto a nivel de la unidad entre países ante el enemigo mayor, la posición de "junción" para salvar nuestras tierras y la identidad de sus pobladores, ya que " $i$ los árboles se han de poner en fila, para que no pase el gigante de las siete leguas! Es la hora del recuento, y de la marcha unida, $y$ hemos de andar en cuadro apretado, como la plata en las raíces de los Andes." 13

Si son parisienses o madrileños, vayan al Prado, de faroles, o vayan a Tortoni, de sorbetes. ¡Estos hijos de carpinteros, que se avergüenzan de que su padre sea carpintero! ¡Estos nacidos en América, que se avergüenzan, porque llevan delantal indio, de la madre que los crió, y reniegan ¡bribones!, de la madre enferma, y la dejan sola en el lecho de las enfermedades!

De lo que se trata es del orgullo de ser americanos, del sano sentimiento de pertenecer a una etnia y a un estrato social y con una misma historia y ancestros. El hombre americano como ente social diferente al "otro" y con parecida "mismi- 
dad" y objetivos comunes. Ni blanco, negro o mulato; ni indio, mestizo o criollo. Todos resultados del desarrollo de su identidad que tiene la marca latinoamericana que está preñada de (casi) iguales tradiciones, transculturación y su común pasado colonial.

Los que niegan su idiosincrasia, su identidad, los llama Martí "<increíbles> del honor"', blo; de igual manera que lo hacen en la actualidad los que la empeñan con las transnacionales e incluso con la imagen cultural que transmiten los medios de difusión extranjeros, con sus videos, sus películas, revistas y programas por Internet perniciosas y modelizantes de ideales de violencia, pasividad anticontestataria y cantos de sirena. Modos de "culturizar" a los pueblos para sus nefastos intereses, donde por ejemplo unos producen alta tecnología y otros consumen desechos. Los "increíbles del honor" se magnetizan por el "american way of life", dejando atrás su ser latinoamericano y aún creen en el esplendor de un neoliberalismo que ha mostrado su incapacidad económica y social de un desarrollo equilibrado y justo para el "hombre natural" de nuestras tierras.

Para el Ministro de Economía y Planificación de Cuba, Dr. José Luis Rodríguez García:

Desde las tesis liberales de Adam Smith, que concebía el libre juego del mercado como el medio ideal para compatibilizar la búsqueda del beneficio individual con el mayor beneficio social, asistimos a la singular transfiguración del egoísmo personal en una virtud social, dando a la equidad, así concebida en los marcos de la concurrencia, un sello de igualdad de dudosa validez. ${ }^{16}$

El crecimiento del mercado propició el económico también. El sistema capitalista se aseguraba buenos dividendos pero a costa de la no equidad en la socialización de los bene- 
ficios y mucho menos un desarrollo equilibrado. En la década del 60 y 70 del siglo XX el intercambio desigual la marcó con un acelerado intercambio. Así en $\operatorname{los} 80$ y 90 la deuda externa crecía en los países latinoamericanos. Ocurre "una fuerte contraofensiva neoliberal junto a un creciente proceso de globalización de la actividad económica" "17 la advertencia martiana sobre el comercio equitativo y justo y el peligro que emanaba desde el vecino del norte y Europa, fue desoído por los gobernantes y economistas locales. El proyecto sociocultural martiano de "Nuestra América" tiene aristas posibles de hacer equivaler a fenómenos de la superestructura que tiene que ver con el desarrollo económico, en múltiples instancias, y el desarrollo de la cultura del hombre de nuestra América. El proyecto del ALCA tuvo sus antecedentes en las Conferencias Monetarias y la política de subordinación de los EE.UU ya en la época martiana.

Lo que ocurre hoy en el Tercer Mundo con su endeudamiento cada vez más progresivo y asfixiante tuvo su génesis, con respecto a América Latina, Martí supo alertarlo a su debido tiempo, y, por eso, pensamos, la organicidad y lógica de su pensamiento llega al clímax en su ensayo mayor "Nuestra América", la cual, por supuesto, no es un tratado de economía, pero ocupa un lugar privilegiado en los escritos del Apóstol y refleja una coherencia del devenir de la sociedad nuestra, donde lo histórico, cultural, económico, forman parte de un todo. Ese todo, es el modelo martiano, tiene una integralidad. En "Nuestra América" el acercamiento es principalmente cultural, ya en otros escritos periodísticos había tratado aspectos económicos que, al alertar sobre ellos, están contenidos aunque no sea explícito en su programa revolucionario y revolucionador del ensayo que estamos analizando.

El espíritu del sufrido hombre de nuestros países, necesita del gobernante que los atienda y no se ajuste a modelos extran- 
jerizantes negativos, ni al "Estado oligárquico, la forma más opuesta que pueda concebirse al equilibrio de los elementos naturales de cualquier país, pues(...) estimulaba y se nutría de los desequilibrios y violencia de todo orden, como lo exigía la vía oligárquica de desarrollo capitalista" ${ }^{18}$ afirma el panameño Guillermo Castro sobre la época que le tocó vivir a Martí.

¿én qué patria puede tener un hombre más orgullo que en nuestras repúblicas dolorosas de América, levantadas entre las masas mudas de indios, al ruido de la pelea del libro con el cirial, sobre los brazos sangrientos de un centenar de apóstoles?' (...) el huen gobernante en América no es el que sabe cómo se gobierna el alemán o el francés, sino el que sabe con qué elementos está hecho su país, y cómo puede ir. guiándolos en junto, para llegar, por métodos e instituciones nacidas del país mismo, a aquel estado apetecible donde cada hombre se conoce y ejerce, y disfrutan todos de la abundancia que la Naturaleza puso para todos en el pueblo que fecundan con su trabajo y defienden con sus vidas. El gobierno ha de nacer del país. El espíritu del gobierno ha de ser el del país. La forma del gobierno ha de avenirse a la constitución propia del país. El gobierno no es más que el equilibrio de los elementos naturales del país. ${ }^{19}$

Pensemos la historia de cada uno de nuestros pueblos y constataremos la justeza de estos enunciados martianos. No se equivocó ni un ápice en su análisis y avisó de las futuras consecuencias para todos nosotros. Los avatares de ayer que Martí observó son la virtual realidad de hoy en algunas naciones.

Mirémonos por dentro y encontraremos varios gobiernos retratados en ese cuadro martiano que contiene varios nudos de contenido aún sin solucionar en Latinoamérica: masas explotadas, gobiernos alejados de su realidad referencial, prácticas inoperantes, desequilibrios y adopción de programas económicos y sociales desvirtuados. Estos desgobiernos no 
pueden satisfacer las solicitudes de Martí, que encarnan la creación de una América Latina con estructuras adecuadas a su realidad y espíritu para un desarrollo justo y un crecimiento continuado sin exclusiones. Por eso, forma y contenido andaban y andan disociados; métodos y prácticas conducentes a un subdesarrollo perenne e insostenible. Ante estos males, consideremos que "la América Latina es una identidad, no sólo por razones históricas y étnico - culturales, sino también porque su presente y su futuro enfrentan (...) la misma amenaza de dominación" ${ }^{20}$ norteamericana.

Vale insistir que muchos de los juicios martianos sobre América latina tienen toda la validez y alcance significativo para las repúblicas antillanas de habla castellana. En las Bases del Partido Revolucionario Cubano se planteaba la independencia de Cuba y Puerto Rico en su artículo primero y en el periódico de la independencia cubana, "Patria", que "las tres Antillas hermanas (las citadas y Santo Domingo)(...) han de salvarse juntas, o juntas han de perecer." ${ }^{21}$. Los males comentados arriba son comunes a todos nuestros países, la identidad se ha construido de manera parecida y el sentido anti- identitario existió y pervive hasta nuestros días, avasallado en grado sumo, por las estrategias neoliberales y la globalización negativa. El papel del imperialismo norteño continúa avanzando contra la identidad latinoamericana y caribeña.

La política económica aceptada por algunas de nuestras naciones hermanas ha traído la negación del desarrollo equilibrado que demandaba Martí. El crecimiento de las capas pobres y de menores ingresos y las medianas, así como la dependencia cada vez mayor de la burguesía a los grupos de poder hegemónicos foráneos y sus instituciones es un hecho incuestionable. Estas circunstancias atentan contra el "ser americano" y antillano al desnaturalizar su esencia y conciencia en diversos órdenes. 
En la época en que fue escrita "Nuestra América" ya el dilema "lo propio" y "lo ajeno", lo nuestro y lo exterior, América mestiza y la rubia del norte y Europa eran cuestiones en discusión que podemos observarlas como dimensiones de la identidad versus procesos internacionalizadores que se afincan en una práctica de imposición de modelos para globalizar y extenderse en el mundo sustentados por prácticas que hoy son neoliberales, pero que han pasado por varios estadíos.

Al escribir el Apóstol que " no hay batalla entre la civilización y la barbarie, sino entre la falsa erudición y la naturale$\mathrm{za}^{\text {"22 }}$ se está refiriendo al eurocentrismo o norteamericanización, propósito "civilizador" del esquema extranjero cargado de tecnología, cultura e intereses diferentes a las propias latinoamericanas y que algunos como Domingo Faustino Sarmiento consideró válido para hacer avanzar nuestros países. Las necesidades nacidas del estadío de esta parte del mundo urgían de respuestas autóctonas y nunca las aplaudidas por la clase oligárquica neocolonial. La dicotomía inicial sarmientina fue su respuesta clasista, la de Martí parte de un pensamiento cultural y va más allá: a lo social, político, etcètera, desde una nueva cosmovisión que facilite un mundo mejor sin el olvido de algún sector y menos aún el marginado, tanto rural como urbano. La expansión neoliberal actual es portadora de esa civilización no autóctona, sino generada en los centros de poder que tienen los recursos económicos y tecnológicos resultado de su desarrollo cognoscitivo o erudito. La mundialización pretende establecer el olvido del hombre natural americano y sus necesidades materiales y espirituales y subordinarlo. La "barbarie", el hombre de nuestras tierras, busca su libertad en la independencia segunda que no podrá encontrar en el nuevo modelo liberal, sino que hallará la globalización de su explotación.

Lo autóctono americano tiene en el pensamiento martiano 
extensiones significativas. No es una posición antidialéctica ni cerrada ante las influencias y desarrollo cultural de lo creado por la humanidad, sino la presencia de una mediación que respeta el "ser" y el "hacer" desde una "mismidad" americana.

Cabe entonces repetir la famosa y paradigmática expresión medular en este ensayo: "Injértese en nuestras repúblicas el mundo; pero el tronco ha de ser el de nuestras repúblicas" "23, la cual sintetiza la cosmovisión sobre el quehacer de las repúblicas hispanoamericanas y del Caribe. Todo el devenir del hombre que sea pertinente, pero practicado sin alejarnos de nuestras raíces. Cultura y ciencia al servicio de lo propio americano, gobiernos salidos de aquí, pensamiento y praxis que atiendan nuestras exigencias, rasgos de la globalización no neoliberal que sean pertinentes y necesarios para nuestro bienestar y desarrollo continuado. Globalización de la solidaridad y la esperanza de una América mejor para el bien de todos.

La cita anterior ha recibido innumerables análisis desde diversas ópticas: ideológica, política, cultural, filosófica. Creemos que cabe también para el esclarecimiento de la actual mundialización o globalización. Es una idea extremadamente importante, a nuestro juicio, para estudiar nuestra posición en el mundo complejo actual y sirve de faro o estrategia.

Estrategia es política. Los pueblos han de vivir criticándose, porque la crítica es la salud; pero con un solo pecho y una sola mente.(...) En pie, con los ojos alegres de los trabajadores, se saludan de un pueblo a otro, los hombres nuevos americanos. Surgen los estadistas naturales del estudio directo de la Naturaleza. Leen para aplicar, pero no para copiar. Los economistas estudian la dificultad en sus orígenes. Los oradores empiezan a ser sobrios. Los dramaturgos traen los caracteres nativos a la escena. Las academias discuten temas viables. La poesía se corta la melena 
zorrillesca y cuelga del ârbol glorioso el chaleco colorado. La prosa, centelleante y cernida, va cargada de idea. Los gobernadores, en las repúblicas de indios, aprenden indio.

De todos sus peligros se va salvando América. ${ }^{24}$

Martí piensa que ha de tenerse en cuenta una estrategia que equivale a política. Los países mestizos pueden tener divergencias y críticas pero desde un mismo haz, desde las intenciones sanas del nuevo hombre americano que se está creando en esa época y que es el mismo de los Foros de Sao Paulo y las conferencias de solidaridad realizadas en la actualidad. Recalca que son los trabajadores, esos hombres nuevos y el papel de los estadistas, los economistas, gobernantes, y dedicados al arte y la literatura; en fin, los trabajadores y una intelectualidad afincada en nuestras realidades para salvar a los países americanos del modelo foráneo y de las circunstancias negativas internas.

El Apóstol cubano está proyectando cómo actuar en América. Su interés parte del discurso real contextual hacia el discurso aspirado. La función política y estratégica es la de avisorar caminos y vías para la solución del problema americano. Martí está construyendo un programa de resistencia y ofensiva basado en la unidad de propósitos e identidades parecidas latinoamericanas y caribeña ante la política del imperialismo norteamericano. Coincidimos con Roberto Hernández Biosca, quien desde el punto de vista cultural, nos expresa: "las estrategias culturales propuestas por José Martí en su ensayo "Nuestra América" marcan las pautas metodológicas esenciales" "2. Estas aún no han sido las armas de combate para todos nosotros; quizás con el estudio profundo del pensamiento martiano, latinoamericano y caribeño logremos salvarnos en la encrucijada actual, aunque advertimos que no es necesario un modelo rígido, ni una única vía. "Crear es la palabra de 564 
pase de esta generación. El vino, de plátano; y si sale agrio. ies nuestro vino!" 26 , como pensaba Martí para sus contemporáneos y que es absolutamente válido para todos nosotros. Las expectativas y urgencias de aquel momento continúan siendo elementos a tener en cuenta. El desequilibrio provocado por el colonialismo y el neocolonialismo hoy pervive, con nuevos matices, en las repúblicas que intentan dejar atrás el lastre de desigualdades insalvables.

El hombre contemporáneo de acá, insistimos, puede hallar su hombradía política arrastrando al gigante de las siete leguas al abismo al frenar los impulsos del nuevo liberalismo venido de los centros de poder.

El deber urgente de nuestra América es enseñarse como es, una en alma e intento, vencedora veloz de un pasado sofocante, manchada sólo con la sangre de abono que arranca a las manos la pelea con las ruinas, y la de las venas que nos dejaron picadas nuestros dueños. El desdén del vecino formidable, que no la conoce, es el peligro mayor de nuestra América; y urge, porque el día de la visita está próximo, que el vecino la conozca, la conozca pronto, para que no la desdeñe. Por ignorancia llegaría, tal vez, a poner en ella la codicia. Por respeto, luego que la conociese, sacaría de ella las manos. ${ }^{27}$

El Hombre mayor de Cuba, al analizar las circunstancias que acaecen en América Latina y el Caribe, observó que la contraposición o el subyugamiento de una raza por otra atentaba contra la unidad nacional y supranacional latinoamericana y también contra la identidad. El considerar una raza superior a otra es un hecho anticultural y anti-identitario. No se trata de las características e idiosincrasia de una raza, sino de considerar a todas con iguales derechos, independientemente de su estadío sociocultural o económico. Para Martí y su proyecto, el ser humano vale en tanto su grandeza y alcance 
humanista. A su modelo le era muy cara la estrategia del dominador de oponer razas entre sí y dividir. Él estudió bastante este tema y dejó varios trabajos que muestran un pensamiento coherente sobre el papel que ocupaba el término raza y el de humanidad.

La identidad universal del hombre para su unión y participación en su programa de liberación continental fue el principio fundamental deseado por el Apóstol cubano. En ella cabían todas las particularidades identitarias de nuestros países y por lo tanto constituía un pensamiento unificador por encima de la categoría raza aplicada a un grupo o sector determinado debido a sus rasgos caracterológicos externos físicos.

No hay odio de razas, porque no hay razas. Los pensadores canijos, los pensadores de lámparas, enhebran y recalientan las razas de librería, que el viajero justo y el observador cordial buscan en vano en la justicia de la Naturaleza, donde resalta en el amor victorioso y el apetito turbulento, la identidad universal del hombre. El alma emana, igual y eterna, de los cuerpos diversos en forma y en color. Peca contra la Humanidad el que fomente y propague la oposición y el odio de las razas. ${ }^{28}$

El mandato superior está muy claro en el texto y culmina al expresar la junción

Para la paz de los siglos, con el estudio oportuno y la unión tácita y urgente del alma continental. ;Porque ya suena el trueno unánime; la generación actual lleva a cuestas, por el camino abonado por los padres sublimes, la América trabajadora; del Bravo a Magallanes, sentado en el lomo del cóndor, regó el Gran Semí, por las naciones románticas del continente y por las islas dolorosas del mar, la semilla de la América nueva! ${ }^{29}$

El Gran Semí ha regado las semillas para hacer crecer al 
hombre americano y caribeño ${ }^{30}$ bajo la "fórmula del amor triunfante: $<$ Con todos, y para el bien de todos $>$ "31.

Corresponde a nosotros considerar una estrategia para la unión, la equidad, la justicia y bienestar para todos y el bien de todos los que portamos el espíritu identitario americano y desde el pensamiento regional alcanzar uno suprarregional que contrarreste las circunstancias actuales de globalización neoliberal. Un pensamiento donde los aportes de las Ciencias Sociales y otras se consoliden y ayuden a la creación de un modelo de raíz martiano donde lo político, ético, económico y social se conjuguen en presente del indicativo, sin formalismos ni dogmatismos.

Así el Gran Semí que invocó José Martí, verá las semillas germinar.

\section{Referencias bibliográficas}

1. Cfr. Roberto Fernández Retamar: Calibán y otros ensayos. La Habana, Editorial Arte y Literatura, 1979.

2. Fernando Ortíz: "Del fenómeno social de la transculturación y de su importancia en Cuba", en Contrapunteo del tabaco y el azúcar. p.88-104.

3. Para referinos al hombre que vive en la zona geográfica al sur de los EE.UU, utilizamos el término "hombre latinoamericano" o" caribeño", "antillano", en fin, el nacido en la América mestiza martiana.

4. Carlos Andújar Persinal: "La identidad dominicana y sus fantasmas". en Ciencia y Sociedad. Vol XXIII, no 4, oct.- dic., 1998. p.485 y otras.

5. Dalia Rodríguez Bencomo: "El tema de la identidad en la obra martiana desde una perspectiva filosófica". Resumen de tesis de Doctorado. Universidad de La Habana, 2004,p. 16.

6. Maritza García Alonso: Identidad cultural e investigación. La Ha- 
bana. Centro de Investigación y Desarrollo de la Cultura Cubana Juan Marinello. 2002. p. 10.

7. Ibid.p. 33-34.

8. Ibid.. p. 36

9. José Martí: "Cuadernos de Apuntes (1881)" en Obras Completas. t. 21. La Habana, Editora Nacional de Cuba, 19, p. 221.

10. José Martí: "Nuestra América", en Obras Completas, t.6.p.15.

11. Ibid

12. Ibid

13. Ibict.

14. Ibid..p. 16

15. Ibid..p. 15 .

16. José Luis Rodríguez García: "Globalización y equidad: breve análisis crítico". en cuba Socialista, \#25, p.26.

17. Ibid.. p. 27

18. Guillermo Castro Herrera: "Cultura y Sociedad en José Martî". en Anuario del Centro de Estudios Martianos, \#5, 1982,p. 150.

19. Ibid., p16-17.

20. Pedro Pablo Rodríguez: "Como la plata en las raíces de los Andes. El sentido de la unidad continental en el latinoamericanismo de José Martí", en Anuario del Centro de Estudios Martianos. \# 3 , 1980.p.327.

21. José Martí: "Las Antillas y Baldorioty Castro", en Op. cit.t 4, p. 407 .

22. José Martí: "Nuestra América", en Op.Cit.. t.6.p.17

23. Ibid.p. 18

24. Ibid.. p.21

25. Roberto Hernández Biosca: "Violencia cultural is. Cultura de resistencia" en Revista Honda, Sociedad Cultural José Martí, no.2. añol. 2000,p.12

26. José Martí: "Nuestra América", en Op.Cit., t.6,p.20 
27. Ibid., p. 22.

28. Ibid., p.22

29. Ibid, t.6, p.23, 1963.

30. Cintio Vitier: "Nuestra América en Martî", en Temas martianos. Segunda Serie. La Habana, Centro de Estudios Martianos. 1982.

31. José Martí: "Discurso en el Liceo Cubano, Tampa", en Op. Cit., T 4, p. 279 . 